University of Windsor

Scholarship at UWindsor

OSSA Conference Archive

OSSA 10

May 22nd, 9:00 AM - May 25th, 5:00 PM

\title{
Don't feed the trolls: Straw men and iron men
}

\author{
Scott Aikin \\ Vanderbilt University, Department of Philosophy \\ John Casey \\ Northeastern Illinois University, Department of Philosophy
}

Follow this and additional works at: https://scholar.uwindsor.ca/ossaarchive

Part of the Philosophy Commons

Aikin, Scott and Casey, John, "Don't feed the trolls: Straw men and iron men" (2013). OSSA Conference Archive. 5.

https://scholar.uwindsor.ca/ossaarchive/OSSA10/papersandcommentaries/5

This Paper is brought to you for free and open access by the Conferences and Conference Proceedings at Scholarship at UWindsor. It has been accepted for inclusion in OSSA Conference Archive by an authorized conference organizer of Scholarship at UWindsor. For more information, please contact scholarship@uwindsor.ca. 


\section{Don't feed the trolls: Straw men and iron men}

\section{SCOTT AIKIN}

Department of Philosophy

Vanderbilt University

Nashville, TN 37240

USA

scott.f.aikin@vanderbilt.edu

\section{JOHN CASEY}

Department of Philosophy

Northeastern Illinois University

5500 N.St.Louis

Chicago, IL 60625

USA

j-casey1@neiu.edu

ABSTRACT: The straw man fallacy consists in inappropriately constructing or selecting weak (or comparatively weaker) versions of the opposition's arguments. We will survey the three forms of straw men recognized in the literature, the straw, weak, and hollow man. We will then make the case that there are examples of inappropriately reconstructing stronger versions of the opposition's arguments. Such cases we will call iron man fallacies.

KEYWORDS: iron man fallacy, straw man fallacy, weak man fallacy

\section{INTRODUCTION}

As some of recent work has shown, there is more to the problem of straw manning than the distortion of an opponent's argument. Some forms of straw man, such as the weak man, rely on accurate, even scrupulously accurate, depictions of arguments for criticism. Other forms, such as the hollow man do not actually involve representations of anyone's actual argument or view. Nonetheless, these strategies, and others to be discussed here, are dialectically problematic for much of the same reasons the distortion form of straw man is, in that they, to use some metaphorical language, misrepresent the dialogical lay of the land. We will argue here that two further features complete the account of the fallaciousness of the straw man: (1) a move to close the argument with the straw man victim (and those with similar views) and (2) a move to paint the straw man victim as unworthy of being taken seriously. What makes the varieties of straw man fallacious can also be used to show that not all forms of straw men arguments ought to be considered fallacious. Finally, the considerations that distinguish fallacious from non fallacious straw men also uncover a related phenomenon, iron manning, or the practice of making an opponent's argument stronger than it is. We will argue that there are both 
appropriate and fallacious versions of this tactic.

\section{VARIETIES OF THE STRAW MAN}

Our aim in this section is to show that (1) there is a variety to the straw man, (2) there's more involved in the phenomenon than manipulation of commitments ploys, and (3) that non fallacious, but formally identical variations of each of these forms exist.

\subsection{The representational form of straw man}

Let's call the textbook form of the straw man the "representational form." This consists in the first instance distortion of an opponent's argument, followed by a decisive refutation. Consider:

APA

Philo: $\quad$ A lot of people have suggested that the American Philosophical Association amend the practically obligatory Eastern APA interview on account of the expense, inconvenience, and stress for all involved.

Sophia: Come now Philo, I hardly think that completely abandoning the system is desirable, so we ought to reject their suggestions.

APA meets the basic schematic requirements for the straw man in that we have (1) two arguers and (2) criticism of one by the other. We can also tell that the criticism here hinges on the representation of the first arguer's position. The first arguer maintains that the APA ought to amend the Eastern APA hiring process because it is expensive, inconvenient, and stressful for everyone. But the second arguer attacks a related, but substantially different claim, namely that abandoning the system is ridiculous. Philo not suggested that the system be completely abandoned; rather, she has suggested that the APA amend the process. Sophia has misrepresented Philo's view, and dismissed the misrepresentation as weak.

\subsection{The weak man}

Consider another variation of the straw man argument. Call it the weak man. In its broad outlines, the weak man consists in (1) selecting the weakest of an opponent's actual arguments, (2) actually defeating it, and (3) then drawing or implying deeper conclusions about the argument or the arguer in question. Consider the following exchange:

Locavorism

Serenity: The culinary and ecological movement known as "locavorism" maintains that favoring sustainably and ethically raised local and seasonal produce is superior 
to the more dominant industrial model.

After all, it does not depend on petroleum-intensive fertilizer, it's not transported across the country (or the world in many cases), and it sustains local agricultural economies.

Archer: The claims of the locavorism movement are ludicrous, the alleged fuel savings in food transportation amount to very little if any overall petroleum savings. Locavorism is loco.

In this case, the locavore maintains that a number of different reasons independently and convergently support the single conclusion that locavorism is a wiser policy than high intensity industrial agriculture. The critic singles out one of them, the alleged fuel savings, and refutes it, implying he has dealt a blow to the argument as a whole. The locavorism critic might even have an especially decisive and sound argument, but even granted that, much would remain to consider in favor of locavorism. The weak manner hopes to exaggerate the importance of the weak argument, but barring that, he can focus critical scrutiny on the ideological fellow travelers of the person making the weak argument

\subsection{The hollow man}

In a third variation of the straw man, one invents an entirely fictitious and decisively silly position, attributes it to a purportedly real, but vaguely defined opponent, knocks it down, and thereby suggests the opposition isn't worthy of rational discussion. The "tell" for this version of the straw man, is often the infamous "some say" or "some might say" phrase that obscures the identity and therefore absolves the speaker of the charge of lying. Many of you are likely familiar with the controversy surrounding Rush Limbaugh's tendency to make jarring remarks. Unsurprisingly many have rushed to his defense. Among them was the Wall Street Journal's Peggy Noonan:

\section{Peggy Noonan}

"Why would the left be worse? Let me be harsh. Some left-wing men think they can talk like this because they're on the correct side on social issues such as abortion. Their attitude: 'I backed you on the abortions you want so much, I opposed a ban on partial birth. Hell, I'll let you kill kids at any point until they're 15, I'm cool. And that means I can call women in public life $\mathrm{t}-\mathrm{-}-\mathrm{s}$, right? Because, you know, I think of them that way."' (WSJ 3/16/2012)

Like the weak man, the hollow man does not involve distorting any argument so much as inventing an entirely new one. In this example, Noonan does not bother to identify the bearer of the view other than to say that "some left-wing men" think this. 


\section{ARE THERE LEGITIMATE USES OF THE STRAW MAN?}

The various schemes of straw men are defined by the way one arguer represents the views of another: badly, selectively, or falsely. The question is whether one can badly, selectively, or falsely represent someone's views without being guilty of fallacy.

Consider: it would be very hard to teach philosophy without employing some variation on the straw man scheme frequently and energetically. With regard to this reason, Ribiero notes that (2008) that distortions formally identical to straw man distortions occur frequently in the classroom from pedagogical need: (1) historical interest, (2) pedagogical ease, (3) and practical availability. There seems, in fact, to be an intuitive case for using the various schemes of the straw man pedagogically. Representational straw men might be employed to drive home particular pedagogical points. A teacher of music, for instance, might exaggerate the bad habit of her music student:

Music Teacher

Music teacher to student: you need to work on your intonation. At the moment it sounds like a tortured cat.

The teacher has distorted the student's behavior by hyperbole, but the point is to fix the student's awareness on her poor intonation. A similar case might be made for the other two straw man ploys. A weak man might be used as practice.

Gay Marriage

Brad: I've heard quite a number of arguments against gay marriage in the conservative press lately. Angelina: I have too. I heard one particularly bad one from a blogger at RedState.com:he argued that if homosexuals are allowed to marry, nothing would prevent him from marrying his box turtle.

Brad: Wow, that's hilarious.

In this example, Brad signals that there are several arguments against gay marriage. We can imagine that some are better than others. Angelina responds by attacking what is likely to be weakest of them, a kind of textbook version of the slippery slope fallacy. Answering it first improves further discussion.

For a hollow man case, continue our pedagogical consideration. Open just about any introductory logic text, and one will find the exercise sections full of arguments few sensible people would make (though we're often disabused of this notion). It's just easier, however, to do it this way, for the point of the fallacy exercise is to get at the form of argument, not to pin failings on specific people

Though all of these examples fit the straw man ploy in its various forms, none of them are in our view fallacious. In Music Teacher, the instructor attacks an exaggerated version of the student's performance to highlight a difficult to appreciate pedagogical point. In Gay Marriage, Angelina goes straight for the 
weakest of the arguments for the anti-gay marriage position, and so weak mans that view. But she does not draw the inference that this view is representative of the best of the opposition. Weak manning sometimes serves the dialectical purpose of clearing away weak arguments, which nonetheless may have a lot of adherents, and which nonetheless occupy much in demand dialectical space.

These representative, but non fallacious, straw man ploys highlight two important features about what makes most straw man arguments fallacious in the first place. The fallaciousness does not primarily consist in the distortion of someone else's argument (as in the representational straw man), in the purposeful selection of the weakest of someone's arguments (as in the weak man), or finally in the invention of weak arguments or arguers (as in the hollow man); all of these can be very useful dialectical tools. What makes these tactics fallacious is how they are deployed. The varieties of straw man are fallacious if they are deployed (1) to close off argument prematurely and (2) illegitimately impugn an opposing arguer's competence. So, for instance, the hollow man is fallacious when one makes up an idiotic argument, knocks it down, in order to suggest that the opposition, however vaguely defined, lacks sufficient critical skill, as in the Peggy Noonan example above. Such people's views are unserious and not worthy of further consideration. The other two examples show a similar tendency to tar the target with an accusation of a bad argument. In APA, the arguer is alleged to have made an extreme suggestion; in Locavorism, the arguer is alleged to be insufficiently reflective or to associate with insufficiently reflective people.

\section{IRON MANNING}

If what makes the varieties of straw men fallacious is their exclusionary, or closing, function, then it is easier to distinguish fallacious cases of straw manning from non fallacious ones.

The fallaciousness of strawman arguments is indexed to context. Views or arguments that warrant careful consideration in one situation may not deserve them in another. This means at times it may be permissible (and necessary) to exclude some views from consideration on the basis of cursory arguments. In other words, while fallacious straw men involve the exclusion of arguments or arguers from justly deserved consideration, in light of the function of the straw man to distort over time, there is good reason to think that unreasonably or overly charitable interpretations of arguments (of arguers) can also qualify as fallacious. It's certainly fallacious, in other words, to distort a person's argument in order more easily to it knock down (and malign the person as a competent arguer); however, by parity of reasoning, a charitable distortion to present an unserious arguer as serious is equally problematic. We call this the iron man. Consider the following cases.

\subsection{Eric Cantor}

Eric Cantor is the Republican Majority Whip in the House of Representatives. In an interview with Leslie Stahl on CBS's 60 Minutes (1/1/2012), Stahl asked Cantor to square the fact that Ronald Reagan raised taxes during a recession with the current 
Republican Party view--allegedly inspired by Reagan--that taxes ought never to be raised. In response, Cantor denied that Reagan ever raised taxes. His spokesperson interrupted the interview, alleging that Stahl did not have her facts straight. She did. Coming to Cantor's defense, one blogger (Jim Hoft) made the following claim:

Stahl, was not being honest. When Ronald Reagan took office, the top individual tax rate was 70 percent and by 1986 it was down to only 28 percent. All Americans received at least a 30 percent tax rate cut. Democrats like to play with the numbers to pretend that Reagans [sic] tax increases equalled [sic] his tax cuts. Of course, this is absurd.

... Unfortunately, Steve Benen at the Washington Monthly continued to misrepresent Reagan's record on tax cuts. It's just soooo difficult for liberals to understand that tax cuts work. Sad.

Notice that Hoft has offered a different and (much more defensible) view on behalf of Cantor: on aggregate, taxes were lower after Reagan's years in office than before. This was not the point under consideration. The net effect of this is to distort the proper evaluation of Cantor's claim and Stahl's criticism.

\subsection{Westboro Baptist Church}

The Westboro Baptist Church is known for demonstrating at the funerals of fallen soldiers. At their protests, they hold up signs alleging that the death of the person is God's punishment for the tolerance of homosexuality in America. In light of this, consider the following exchange.

\begin{tabular}{|c|c|}
\hline Sally: & $\begin{array}{l}\text { The Westboro Baptist Church boycotted my local } \\
\text { synagogue, carrying signs that say "God hates fags." } \\
\text { Their views are patently ridiculous; far from even the } \\
\text { fringe of conservative Christianity. People should just } \\
\text { ignore them. }\end{array}$ \\
\hline Priscilla: & $\begin{array}{l}\text { Yes, but aren't they really suggesting that our fate as a } \\
\text { nation is bound up with the moral fibre of the American } \\
\text { people? As we lose our sense of commitment, } \\
\text { steadfastness, and courage, we will not realize our } \\
\text { plans. }\end{array}$ \\
\hline
\end{tabular}

Priscilla raises some interesting points, but they are vaguely related to the actual content of the Westboro Church's protests and Sally's objection. The question is whether these particular arguments from the Westboroites deserve consideration. And so iron-manning can be an occasion for broader discussion, but one iron mans so that we do not have to discuss this particular argument. 


\subsection{Philosophy student I}

We have discussed above how teaching philosophy to undergraduates often depends on strategically employed, non-fallacious straw men. As it is necessary sometimes to straw man views, it is also necessary to iron man the student's view. With this in mind, imagine the following teacher-student exchange.

Alfredo: Rawls' "Original Position" seems impossible to me. I mean, how are we to know what sorts of things we'll be interested in if we don't know anything about ourselves?

Professor Zoccolo: That's an interesting point, Alfredo, you're suggesting that Rawls's Original Position does not take cognizance of how we are constituted by our social relations. Thinking them through abstractly seems problematic.

Alfredo's view certainly trends communitarian, but it would be a stretch to suggest that this is what he meant. Unlike the previous cases, however, iron-manning Alfredo shows him how to improve his contributions to the discussion.

\subsection{Philosophy student II}

The norm of iron-manning student views can yield good results. It shows students how to improve their thoughts. However, it can yield classroom disaster, as it can encourage more poorly stated views. Iron-manning the student makes it such that the teacher does the work in crafting the views. Moreover, time in the classroom is too short to take all the off-the-wall views seriously. Sometimes, iron-manning undercuts a serious classroom. Consider:

Professor Barleycorn: Descartes' argument in the First Meditation is that very little of what we take ourselves to know securely is certain. It may all be a dream. Or it may all be an illusion of a very powerful demon.

Bradley: Dude! I had a dream like that one night - that I was in the clutches of an evil demon. And he made me do things... like terrible things... to chickens. And then, when I woke up... it was all true. The terrible stuff to chickens stuff, that is. That was all after I drank too much cough syrup with my beers. Did Day-Cart have a Robitussin problem?

Bradley is way off base. For sure, his weird story deserves a moment of reply, but it is best for all involved that a lengthy analysis of Bradley's views on the matter aren't 
devoted class time. Some views are best left unexamined. Next time, Bradley should read. And lay off the syrup.

\section{DISCUSSION}

From these cases, the basic form of iron man argumentation can be discerned. First, as a dialectical form, the iron man requires two speakers, A and B. A proposes some argument $a$ and/or some position $p$. But $a$ and $p$ are not defensible. B takes up with A's case with a reconstruction, $a^{*}$ and $p^{*}$, that given the state of dialectical play are (comparatively more) defensible. Often this strategy is done for the sake of an onlooking audience, $\mathrm{C}$, which may be interested in A's views or the issue of whether that $p$. So far, again, we can see that there is a dialectical distortion, just as there is with straw-manning, but instead of degrading the opponent's argument (as with the straw man), the opponent's case is improved. Hence our term iron man.

There are compelling epistemic reasons to regularly iron man one's opposition, as the truth will come out in contexts of maximally responsible and detailed argumentation. Since our epistemic objectives in argument are truth and its understanding, the most intellectually robust opponent is the best, and if one does not encounter but must construct such an opponent, then so be it. Moreover, there are ethical (and political) reasons why iron-manning may be appealing. At its core, iron-manning is a form of interpreting others communicative acts with charity. The demands of recognition, further, for underrepresented groups obtain so that their interests can be heard and have effect. Iron-manning is in the service of this. Finally, again, there are pedagogical reasons why iron-manning may be required.

So what, then, could be wrong with iron-manning? We hold that there is a fallacy of inclusion for the same reason that there is a fallacy of exclusion.

Let us return to the cases. As we saw with Philosophy Student II, there are pedagogical reasons why iron-manning can be objectionable, as the point of class discussion is for students to improve their own views, not having it done for them. It is here that we begin to see the trouble with some forms of iron-man: in taking some poorly articulated views seriously, improving them and submitting them to scrutiny, one makes an investment of time and intellectual energy. The trouble is that there are many investments that are unwise. Consider, further, a feature of discussion after content presentation. There is evidence now that suggests that rude or irrelevant online comments after a posting or story actually distort reading comprehension of the original piece. That is, the more comments that don't get the original point you are exposed to or the more rude comments in the discussion thread, the less likely it is that you will, afterwards, correctly recall the details of the posting. This is now being called, "The Nasty Effect." Derailed discussion not only is a waste of time, but it is miseducation.

Now consider the strategic use of iron-manning with the Eric Cantor case. The trouble is not with improving the view per se, but with the way the improvement is deployed. In this case, (a) the iron man is presented as Cantor's view, and (b) thereby it is used as evidence that Stahl is (and liberals generally are) fact challenged. But this is a distortion not only of Cantor's position, but of Stahl's, too. By iron-manning Cantor, one straw-mans Stahl, his critic. Her criticisms now 
seem off-target and ill-informed, when they, in fact, were not.

These two elements of iron-manning converge. When one iron mans a poorly presented view, one may encourage those who have posed the view by taking them seriously, and thereby impugn their critics. Again, sometimes this is appropriate, as some views need time and patience for their development and some speakers require maximal charity in interpreting their communicative acts. But sometimes it is inappropriate, as one can be held hostage by these speakers. On blog comment threads and chatboards, there are many who are uninformed and contribute with unhinged criticism. They are out to hijack discussion, to hold forth, to be the center of attention. These are, in internet lingo, trolls. Taking the trolls seriously, interpreting them with charity, and responding to them thoughtfully yields only grief. One must not feed the trolls.

Indeed, too often philosophers and informal logicians overlook the fact we very often find ourselves having to evaluate just this argument from this arguer, even if this argument could be stronger, or this arguer could use some help. We have argued here that even charitable alterations of arguments or arguers distort the dialectical landscape are often unacceptable, for exactly the same reason why strawmanning is unacceptable. The only difference is that the straw man excludes arguments worth listening to; the iron man includes arguments not worth listening to. In all, we've identified a few rough criteria for knowing when iron-manning is fallacious:

1. When it is clear that the argument to be reconstructed is not likely to be either relevant or successful.

2. When it is clear that the improvement of and response to the argument will take more time than is allotted, and there are other, more clearly salient, issues.

3. When, even if $1 \& 2$ do not obtain (that is, when there may be something relevant and there is plenty of surplus time and energy), it is clear that responding to this speaker under these circumstances encourages further badly formed arguments.

4. When the positive reconstruction of the argument (iron man) in question yields mis-portrayal of the arguments prior critics as attacking a straw man.

This rough set of criteria are, in the end, an overlap of (a) issues in cognitive economy (maximizing epistemic efficiency), and (b) issues in maintenance of a properly run dialectical field. We hold $1 \& 2$ are epistometric questions, and $3 \& 4$ are dialectical questions. Hence, the basic thought that sometimes feeding the trolls is (a) a waste of time and energy, and (b) it ultimately isn't anything but bad for the way we argue.

\section{CONCLUSION}

We have argued in this paper that the dialectical phenomenon known as straw manning is much more varied than many accounts suggest. In the first place, straw 
manning involves more than simple distortion. It also includes forms of selection (weak manning) and invention (hollow manning). Second, not all instances of straw manning are fallacious. Finally, and somewhat ironically, charitable variations on an argument suffer from the same failings as fallacious straw men, though their mistake lies in the inclusion of arguments deserving of exclusion.

\section{REFERENCES}

Aikin, Scott and John Casey. (2011) "Straw Men, Weak Men, and Hollow Men". Argumentation, 25, 87105.

CBS News, 60 Minutes . (2012) Interview with Eric Cantor. http://www.cbsnews.com/830118560_162-57348499/the-majority-leader-rep-eric-cantor/?tag=contentMain;cbsCarousel

Bizer, George Y., Kozak, Sirel M., and Holterman, Leigh Ann (2009) "The Persuasiveness of the Straw Man Rhetorical Technique." Social Influence, 4, 216-230.

Drum,Kevin. http://www.washingtonmonthly.com/archives/individual/2006 08/009324.ph p

Elliot, Deborah. (2011) "GOP Splits up for Weekend Conferences." NPR Weekend Edition. http://www.npr.org/2011/06/18/137265773/gop-splits-up-for-weekendconferences

Govier, Trudy (1997) A Practical Study of Argument, 4e. Belmont, CA: Wadsworth.

Lewinski, Marcin (2011). "Towards a Critique-Friendly Approach to Straw Man Fallacy Evaluation." Argumentation, 25, 469-497

Ribeiro, Brian (2008) "How Often Do We (Philosophy Professors) Commit the Straw man Fallacy? Teaching Philosophy, 31, 27-38.

Talisse, Robert and Scott Aikin (2008) "Two Forms of the Straw Man." Argumentation, 20, 34552.

Talisse, Robert and Yvonne RaleY (2008) "Getting Duped: How the Media Messes with Your Mind." Scientific American Mind. January/February.

Tindale, Christopher (2007) Fallacies and Argument Appraisal. Cambridge University Press.

Van Eemeren, Frans, Rob Grootendorst, and Francisca Snoeck Henkenmans (2002) Argumentation: Analysis, Evaluation, Presentation. Mahwah, NJ: Lawrence Erlbaum.

Van Eemeren, Frans, Rob Grootendorst (2004) A Systematic Theory of Argumentation. Cambridge University Press.

Van Eemeren, Frans, Rob Grootendorst (1992) Argumentation, Communication, and Fallacies. Hillsdale, NJ: Lawrence Erlbaum.

Van Eemeren, Frans and Houtlosser, Peter (2007) "The Contextuality of Fallacies." Informal Logic, 27, 59-67.

Van Laar, Jan Albert (2008) "Room for Maneuver When Raising Critical Doubt." Philosophy and Rhetoric, 41, 195-211.

Walton, Douglas (1989) Informal Logic. Cambridge University Press.

Walton, Douglas (1996) "The Straw Man Fallacy." Logic and Argumentation. Ed. Johan van Bentham, Frans van Eemeren, Rob Grootendorst, and Frank Veltman. Amsterdam: Royal Netherlands Academy of Arts and Sciences, North Holland. 115-28.

Walton, Douglas (1998) Ad Hominem Arguments. University of Alabama Press.

Walton, Douglas and Fabrizio Macagno (2010) "Wrenching from Context: The Manipulation of Commitments." Argumentation, 24, 283-317

Walton, Douglas and Krabbe, Eric (1995) Commitment in Dialogue. Albany: State University of New York Press.

Walton, Douglas; Reed, Chris; Macagno, Fabrizio (2008) Argumentation Schemes. Cambridge University Press. 